\title{
Pressão social do grupo de pares na iniciação sexual de adolescentes*
}

\author{
PEER SOCIAL PRESSURE ON THE SEXUAL DEBUT OF ADOLESCENTS \\ PRESIÓN SOCIAL DEL GRUPO DE PARES EN LA INICIACIÓN SEXUAL DE ADOLESCENTES
}

\section{Ana Luiza Vilela Borges'}

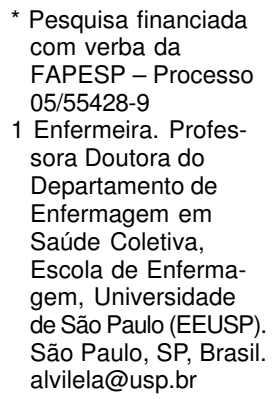

1 Enfermeira. Professora Doutora do

Departamento de

Enfermagem em

Saúde Coletiva,

Escola de Enfermagem, Universidade de São Paulo (EEUSP). São Paulo, SP, Brasil. alvilela@usp.br

\section{RESUMO}

Dado que a literatura enfatiza a estreita relação entre o início da vida sexual e a pressão exercida pelos pares, o objetivo deste trabalho foi identificar a presença da pressão social na iniciação sexual de adolescentes, com base nos relacionamentos com o grupo de iguais. Participaram 363 pessoas, com idade entre 15 e 19 anos, compreendendo uma amostra representativa dos adolescentes cadastrados em uma unidade do Programa de Saúde da Família da cidade de São Paulo. Foi utilizado um questionário estruturado e auto-aplicado. Os resultados mostraram associação entre a iniciação sexual e idade, já ter ficado com alguém sem vontade, ter a maior parte dos amigos com experiência sexual e estar namorando, o que revelou indícios de que os pares parecem exercer certa influência na opção pela iniciação sexual.
\end{abstract}

\section{DESCRITORES}

Saúde do adolescente. Saúde sexual e reprodutiva. Comportamento sexual.

\section{ABSTRACT}

Considering that scientific articles have emphasized the link between the onset of sexual life and peer pressure, the aim of this study was to identify peer pressure in the adolescents' sexual initiation from the point of view of their relationship with the group of friends. A cross-sectional study was conducted among 363 15-19 year-old teens that represented a sample of the adolescents enrolled in a family health unit in Sao Paulo City, Brazil. Results showed a relation between sexual initiation and age, being involved in physical experience with someone without wishing, having the majority of riends with sexual experience and dating. Eventually, data show that peers might play some influence on adolescents' option for sexual debut.
\end{abstract}

\section{KEY WORDS}

Adolescent health.

Sexual and reproductive health. Sexual behaviour.

\section{RESUMEN}

Considerando que la literatura enfatiza la estrecha relación entre el inicio de la vida sexual y la presión ejercida por los pares, fue realizada una investigación para identificar la presencia de la presión social para la iniciación sexual de adolescentes, a partir de relacionamientos con su grupo de pares. Participaran 363 individuos, con edad entre 15 y 19 años, una muestra fue representativa de los adolescentes registrados en una unidad del Programa de Salud de la Familia de la ciudad de São Paulo. Fue utilizado cuestionario estructurado y auto-aplicado. Los resultados mostraron asociación entre la iniciación sexual y la edad, ya haber estado con alguien sin voluntad, tener amigos, en su mayoría con experiencia sexual y estar enamorando, lo que revela indicios de que los pares parecen ejercer cierta influencia para optar por la iniciación sexual.

\section{DESCRIPTORES}

Salud del adolescente.

Salud sexual y reproductiva.

Conducta sexual. 


\section{INTRODUÇÃO}

Partindo do princípio que a iniciação sexual não se dá de forma homogênea entre homens e mulheres, grupos sociais ou gerações, considera-se que um conjunto de elementos complexos é determinante na tomada de decisão de iniciar a vida sexual ou adiá-la para um contexto ou momento considerado mais adequado. Relativamente aos adolescentes, numerosos aspectos têm sido descritos como associados ao início da vida sexual, entre eles, algumas características como idade, raça/cor, sexo, religião, escolaridade e situação de trabalho, bem como aquelas relativas à comunicação e relacionamento entre pais e filhos, à supervisão parental e à estrutura familiar ${ }^{(1-3)}$

Outros aspectos pouco discutidos na literatura referemse às influências que os pares exercem no comportamento sexual dos adolescentes. Tais influências têm sido descritas como um aspecto associado não apenas à iniciação sexual, mas também ao uso de contraceptivos, mais especificamente, o uso de preservativos masculinos ${ }^{(1,3-5)}$. A influência dos pares pôde ser identificada por meio do relato de adolescentes que se sentiram pressionados pelos amigos a iniciar a vida sexual ${ }^{(5)}$, sendo que os homens pareceram ser mais propensos a se submeter a essa pressão que as mulheres ${ }^{(4)}$.

Estudos já relataram que adolescentes com experiência sexual achavam que a maioria de seus amigos também já era experiente sexualmente, em uma proporção muito maior do que adolescentes que ainda eram virgens, independentemente do sexo ${ }^{(1,4)}$. Também afirmaram que quando adolescentes mais novos percebiam que a maior parte de seus pares tinha vida sexual, eles passaram a demonstrar a intenção de também iniciar a vida sexual e, conseqüentemente, concretizaram esse desejo.

Esses autores confirmam que a iniciação sexual pode ser estimulada, entre outros, em razão da difusão de um modelo de comportamento sexual ditado pelos pares que, por sua vez, também estão sujeitos às normas sociais que modelam condutas sexuais.

A presente investigação partiu do princípio que homens e mulheres adolescentes são, em certos momentos, pressionados a iniciar sua vida sexual, não apenas como conseqüência de coerção direta de seus parceiros, mas principalmente por conta de valores disseminados em meio a códigos de conduta e expectativas sociais, que prescrevem uma idade normativa de iniciação sexual bem como circunstâncias adequadas aos homens e às mulheres no tocante à decisão de dar início às suas práticas sexuais.

Este estudo pretendeu, assim, identificar a presença de pressão social para a iniciação sexual entre homens e mulhe- res adolescentes, vislumbrada a partir dos relacionamentos com o grupo de iguais.

\section{MÉTODO}

Trata-se de estudo transversal, desenvolvido em uma amostra representativa dos adolescentes entre 15 e 19 anos de idade de ambos os sexos, moradores da área adscrita de uma unidade de saúde da família da zona oeste do Município de São Paulo (SP). Os sujeitos entrevistados foram selecionados por amostragem sistemática sem reposição, com base em uma listagem obtida por meio do Sistema de Informação da Atenção Básica (SIAB) e ordenada por micro-área e pelo número das famílias cadastradas no Programa de Saúde da Família que tinham ao menos um adolescente entre 15 e 19 anos de idade.

O tamanho amostral foi calculado baseando-se na precisão desejada para se estimar a porcentagem de adolescentes de 15 a 19 que já tivessem iniciado a vida sexual. Tal proporção foi considerada igual a $60 \%{ }^{(6)}$, com erro máximo em valor absoluto de 5\% e com nível de confiança de $95 \%$. Para se obter a estimativa final do tamanho da amostra, esse valor foi ajustado usando-se um fator de correção para população finita. Ainda, considerando a possibilidade de perdas, foram acrescidos $30 \%$ para que não houvesse redução do tamanho da amostra.

Ao todo, 396 questionários estruturados, pré-testados e validados foram entregues aos adolescentes para que fossem auto-preenchidos em seus próprios domicílios (mediante a autorização dos pais ou responsáveis, daqueles que tinham menos de 18 anos de idade) por agentes comunitários de saúde para serem coletados em envelopes lacrados na semana seguinte. Foram coletados ao todo 363 questionários de adolescentes entre 15 e 19 anos, em maio de 2007 (houve 33 perdas). Por conta dos objetivos do presente estudo, que consistem em identificar indícios de pressão social para a iniciação sexual, era primordial que os entrevistados estivessem em uma fase em que o grupo de pares adquire extrema importância. Assim, os dados apresentados a seguir serão concernentes apenas aos 335 adolescentes solteiros.

Os dados foram descritos por meio de proporções e a análise das variáveis associadas à iniciação sexual foi realizada por meio de regressão logística múltipla no SPSS 15.0. Foi considerada variável dependente o início da vida sexual ( $\operatorname{sim} /$ não) e como variáveis independentes as variáveis sociodemográficas (idade, cor, religião, estudo atual, trabalho atual, escolaridade materna e paterna, tipo de domicílio), relacionadas aos comportamentos afetivo-amorosos (já ficou com alguém antes, já ficou com alguém mesmo sem vontade, namoro atual, namoro anterior) e relacionadas aos pa- 
res (maior parte dos amigos já iniciou a vida sexual, amigos são capazes de influenciar adolescentes a iniciar a vida sexual, sente-se pressionado(a) a iniciar a vida sexual). Primeiramente, apenas as variáveis que apresentaram $p<0,20$ nas análises bivariadas foram consideradas na elaboração do modelo múltiplo de regressão logística e foram acrescentadas por stepwise forward.

Esta pesquisa foi aprovada pela Comissão de Ética e Pesquisa da Prefeitura Municipal de São Paulo, tendo sido garantidos os aspectos relativos ao anonimato e privacidade dos sujeitos, além da participação voluntária no estudo. (CAAE 0127/2005, Parecer 0156/2005)

\section{RESULTADOS}

Um pouco menos da metade dos entrevistados era composta por homens $(46,8 \%)$, ao passo que a proporção de mulheres alcançou 53,2\%. A idade média foi 16,8 anos de idade, sem diferença estatisticamente significativa entre os sexos. Apenas $41,2 \%$ coabitavam com ambos os pais e $27,0 \%$ já se encontravam ausentes da instituição escolar. Mesmo entre os que eram estudantes, foi observada uma defasagem entre idade e anos de estudo, principalmente entre os homens. Os adolescentes que se encontravam inseridos no mercado de trabalho totalizaram $27,0 \%$, proporção maior também entre os homens.

Os resultados mostraram que, para metade dos adolescentes, garotos e garotas têm relação sexual mesmo sem estar a fim. De acordo com a Figura 1, mais da metade referiu que os amigos são capazes de influenciar uma pessoa a iniciar a vida sexual. Apenas 4,7\% relataram que nem homens nem mulheres sofrem pressão para ter a primeira relação sexual. Mais homens $(44,6 \%)$ que mulheres $(25,9 \%)$ revelaram ter ficado com alguém mesmo sem vontade (Figura 2).

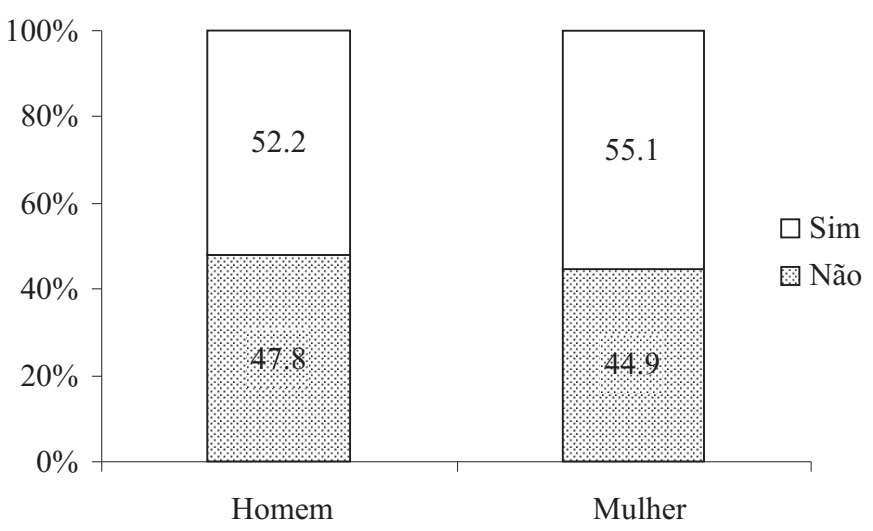

Figura 1 - Proporçãode entrevistados segundo a opinião de que os amigos podem influenciar na iniciação sexual de adolescentes, por sexo - São Paulo - 2007

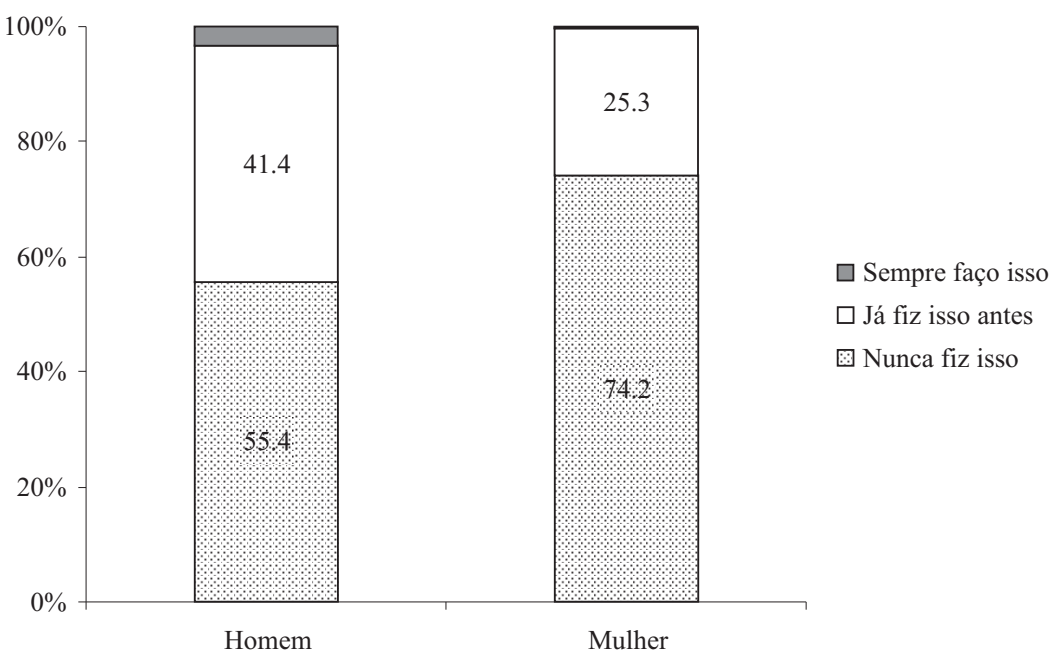

Figura 2 - Proporçãode entrevistados segundo relato de já ter ficado comalguém mesmo sem vontade, por sexo São Paulo - 2007 
A análise de regressão logística múltipla revelou que a idade, o fato de já ter ficado com alguém mesmo sem vontade, ter a maior parte dos amigos com experiência sexual e estar namorando naquele momento foi associado à iniciação sexual, conforme mostra a Tabela 1.

Tabela 1 - Modelo final de regressão logística múltipla da iniciação sexual dos adolescentes entrevistados - São Paulo $-2006$

\begin{tabular}{|c|c|c|c|}
\hline Variável & Categoria & OR & IC $95 \%$ \\
\hline \multirow[t]{5}{*}{ Idade } & 15 & 1,0 & referência \\
\hline & 16 & 1,5 & $0,6-3,7$ \\
\hline & 17 & 2,3 & $0,9-5,7$ \\
\hline & 18 & 6,9 & $2,5-19,0$ \\
\hline & 19 & 4,9 & $1,5-15,9$ \\
\hline \multirow[t]{2}{*}{ Já ficou com alguém mesmo sem vontade } & Não & 1,0 & referência \\
\hline & Sim & 4,5 & $2,1-9,7$ \\
\hline \multirow[t]{2}{*}{ Maior parte dos amigos já iniciou a vida sexual } & Não & 1,0 & referência \\
\hline & Sim & 4,7 & $1,4-16,1$ \\
\hline \multirow[t]{2}{*}{ Namoro atual } & Não & 1,0 & referência \\
\hline & Sim & 6,4 & $3,2-12,8$ \\
\hline
\end{tabular}

\section{DISCUSSÃO}

A pressão social para a iniciação sexual entre os adolescentes entrevistados existe. Esse achado está em acordo com um estudo conduzido na cidade de São Paulo em que os adolescentes iniciaram sua vida sexual, de certa forma, contra sua plena vontade, visto que aproximadamente $20 \%$ disseram que não queriam ter tido a primeira relação sexual, mas deixaram que ela acontecesse, com uma proporção igual entre homens e mulheres ${ }^{(6)}$.

Os resultados aqui apresentados indicam que vários aspectos podem agir como elementos de pressão para a decisão de ter a primeira relação sexual entre os adolescentes entrevistados. O primeiro a ser discutido será a idade.

Não causa surpresa que a idade tenha se mostrado associada ao início da vida sexual, pois é um evento que vai ganhando maior dimensão de forma gradual na adolescência, principalmente após os 18 anos de idade. Esse dado reflete a necessidade de se estabelecer ações de promoção da saúde sexual que alcancem os adolescentes antes que tenham tido práticas sexuais que tragam algum tipo de vulnerabilidade às doenças sexualmente transmissíveis, HIV/ aids e gestações não planejadas, e não apenas quando procuram a unidade básica de saúde por conta de suspeita de gravidez, para a realização do pré-natal ou para aquisição de preservativos masculinos ${ }^{(7)}$.

Outro ponto a ser destacado é que a idade parece se configurar como parte da idealização da iniciação sexual, em que vigora um padrão cultural de uma faixa etária mais adequada para a primeira relação sexual. Em um estudo conduzido também na cidade de São Paulo ${ }^{(6)}$, os entrevistados foram questionados sobre a idade mais adequada para homens e mulheres iniciarem a vida sexual. A maior parte $(65 \%)$ não considerou haver uma idade certa para a ocorrência de tal evento, mas sim contextos ideais, tais como o namoro, a ligação amorosa com o parceiro ou o matrimônio. Entretanto, os outros $35 \%$ relataram que a idade ideal seria em torno dos 17 anos, sejam homens ou mulheres, com experiência sexual prévia ou não. A autora concluiu que pode estar ocorrendo a formação de um padrão que confere maior valor à idade compreendida ao redor dos 17 anos como o momento adequado para a iniciação sexual entre os entrevistados, servindo, inclusive, como elemento de pressão entre aqueles que não tenham iniciado a vida sexual. Esse fenômeno foi chamado de idade normativa de iniciação sexual, que representa um dos componentes difundidos por um código de normas que direcionam e moldam o comportamento sexual de adolescentes ${ }^{(1)}$.

Os adolescentes que relataram já terem ficado com alguém mesmo sem vontade apresentaram uma chance 4,5 vezes maior de já ter iniciado a vida sexual em relação aos que não relataram tal comportamento. Já foi descrito que o ficar é um tipo de relacionamento que não pressupõe compromisso entre as partes, mas faz parte do roteiro de experimentação sexual de adolescentes ${ }^{(8)}$. Chama a atenção que uma proporção razoável de adolescentes referiu já ter ficado com alguém mesmo sem vontade, sendo a proporção maior entre os homens.

O mecanismo como esse evento opera na iniciação sexual ainda precisa ser melhor esclarecido, mas não se pode negar que se trata de um forte indício de que os adolescentes são pressionados a interagirem, com menor ou maior intimidade física, com pessoas e em contextos não totalmente desejados, provavelmente porque recusar esse papel pode ser algo que poderia interferir nas relações com os iguais e, quem sabe, na própria honra masculina, afinal, a iniciação sexual dos garotos serve também como modo de expressão 
do processo de tornar-se homem, de consolidação da masculinidade, o que só pode ser alcançado entre os pares ${ }^{(9)}$.

A associação estatisticamente significativa entre ter a maior parte dos amigos com experiência sexual e já ter iniciado a vida sexual é compatível com outra investigação ${ }^{(1)}$, cuja população de estudo foi composta de adolescentes que cursavam a 6 $6^{\mathrm{a}}$ série em 12 escolas públicas na Filadélfia, Estados Unidos, em 1994 e 1995. Os autores observaram uma percepção presente apenas nos garotos de que a experiência sexual poderia aumentar seu status entre seus amigos e colegas e também relataram que estudantes do sexo masculino com experiência sexual tinham maior probabilidade de acreditar que garotos com vivência sexual ganham respeito, comparados aos garotos sem tal experiência.

Considerando o relato de homens chilenos heterossexuais que já viviam com suas companheiras ou esposas ${ }^{(10)}$, foi ressaltado que a convivência entre os pares seria o lugar mais importante em relação à socialização da sexualidade. Segundo esse autor,

aquilo que não pôde ser conversado e aprendido em casa ou no colégio seria encontrado entre os iguais. Esse espaço permitiria incorporar novas interpretações sobre o corpo e o desejo e/ou reafirmar as aprendidas. Aqui se incorporariam padrões e sentidos subjetivos. É o espaço em que se observam os adultos e se aprendem seus comportamentos, é onde se iniciam as competições entre os homens.

Em relação ao namoro, destaca-se que é o tipo de relacionamento afetivo e amoroso mais freqüente na adolescência-juntamente com o ficar-em que são abertos caminhos para a mútua exploração sexual. Em consonância, parece que a progressão da intimidade do casal de namorados leva inevitavelmente (grifo da autora) ao relacionamento sexual, sendo um

\section{REFERÊNCIAS}

1. Kinsman SB, Romer D, Furstenberg FF, Schwarz DF. Early sexual initiation: the role of peer norms. Pediatrics. 1998; 102(5):1185-92.

2. Santelli JS, Lowry R, Brener N, Robin L. The association of sexual behaviors with socioeconomic status, family structure and race/ethnicity among US adolescents. Am J Pub Health. 2000;90(10):1582-88.

3. Wellings K, Nanchahal K, Macdowall W, McManus S, Erens $\mathrm{B}$, Mercer $\mathrm{CH}$ et al. Sexual behaviour in Britain: early heterossexual experience. Lancet. 2001;358(9296):1843-50.

4. Werner-Wilson RJ. Gender differences in adolescent sexual attitudes: the influence of individual and family factors. Adolescence. 1998;33(131):518-31.

5. Karofsky PS, Zeng L, Kosorok MR. Relationship between adolescent-parental communication and initiation of first intercourse by adolescents. J Adolesc Health. 2001;28(1): 41-5. processo que compreende várias tentativas e evolui com a negociação entre o casal decorrente das expectativas que entram em conflito diante do desconhecido, gerando medo, ansiedade, curiosidade e desejo ${ }^{(8) "}$.

Nesse cenário de aprofundamento da intimidade em uma relação de namoro, destaca-se que, muito antes da primeira relação sexual, a maior parte dos adolescentes já se engajou em experiências ditas pré-sexuais, como carícias e toques mais íntimos ${ }^{(11)}$.

Cabe ressaltar que o namoro foi também referido pelos adolescentes como o contexto idealizado para a primeira relação sexual, visto que em torno de $40 \%$ relataram que o momento ideal para o início da prática sexual deveria ser em um relacionamento de namoro ${ }^{(6)}$. É possível, pois, considerar que o namoro necessitaria estar entre os tópicos abordados nos atendimentos de adolescentes, não apenas porque é um contexto idealizado ou referido de iniciação sexual, mas também porque é um espaço de exercício das relações entre homens e mulheres que, sejam mais igualitárias ou mais hierarquizadas, poderão ser transpostas às atitudes e práticas no comportamento sexual e reprodutivo.

\section{CONCLUSÃO}

Não se pode negar que os adolescentes estão inseridos em uma rede de vínculos de amizade, que constitui, entre inúmeros outros, um espaço fundamental de socialização e que um indicador significativo do processo de socialização para a sexualidade é a convivência com os pares. E são esses pares que, muito possivelmente, não apenas estão sujeitos aos padrões normativos em relação ao comportamento sexual, mas também os reforçam em suas relações com seu grupo de iguais.

6. Borges ALV. Adolescência e vida sexual: análise do início da vida sexual de adolescentes residentes na zona leste do município de São Paulo [tese]. São Paulo: Faculdade de Saúde Pública, Universidade de São Paulo; 2005.

7. Borges ALV. Relações de gênero e iniciação sexual de mulheres adolescentes. Rev Esc Enferm USP. 2007;41(4):597-604.

8. Heilborn ML. A primeira vez nunca se esquece. Rev Estud Fem. 1998;6(2):394-405.

9. Rieth F. Ficar e namorar. In: Bruschini C, Hollanda HB, organizadores. Horizontes plurais: novos estudos de gênero no Brasil. São Paulo: Editora 34; 1998. p. 113-33.

10. Olavarría J. Desejo, prazer e poder: questões em torno da masculinidade heterossexual. In: Barbosa RM, Parker R, organizadores. Sexualidades pelo avesso: direitos, identidades e poder. Rio de Janeiro: Editora 34; 1999. p. 154-74.

11. Schwartz IM. Sexual activity prior to coital initiation: a comparison between males and females. Arch Sex Behavior. 1999; 28(1):63-9. 